\title{
Towards a Better Assessment of Pain and Suffering Damages
}

\author{
by \\ Vaia Karapanou and Louis Visscher*
}

\begin{abstract}
Even though there is general consensus that pain and suffering damages for personal injuries should primarily be based on the severity and duration of the impairment to health, the amounts granted differ greatly between and within countries. There is no legal framework to assess the correctness of the damages because a yardstick is lacking. The authors argue that the concept of Quality Adjusted Life Years (QALYs) from the field of health economics is able to provide the required framework. The primary legal objective of damages is to restore the victim as closely as possible to the position be would have been in without the accident. Besides compensation, satisfaction and prevention are also regularly mentioned as goals of pain and suffering damages. Whatever the goal, the authors' view is that pain and suffering damages must be based on the impact of the health impairment on the victim. The concept of $Q A L Y$ s allows pain and suffering damages to be based on the impact of the bealth impairment. A QALY expresses the value of living one year in a certain bealth condition. The bealth economics literature allows an assessment of the impact of different health conditions on quality of life. By subsequently monetizing QALYs, this impact is expressed in monetary terms, which provides a systematic basis for pain and suffering damages. The authors compare pain and suffering damages in several European countries with the amounts that would result from a conservative estimate of the monetary value of a QALY for specific types of personal injuries. They show that the amounts that are currently awarded are too low when compared to this assessment of the impact of the injury on quality of life.
\end{abstract}

(2010) 1 JETL 48

\section{Introduction}

In this paper we investigate the size of pain and suffering damages for personal physical injuries. We limit ourselves to physical injuries occurring in a system of tort law. ${ }^{1}$ The difficulty faced by courts in assessing pain and suffering damages lies in the non-pecuniary nature of the losses. They may include pain, suffering, anxiety, fear, emotional strain, physical and psychological reduction of health and loss of enjoyment of life and these effects may occur for a limited

* Vaia Karapanou is a PhD student in the European Doctorate in Law and Economics (EDLE) and is attached to the Rotterdam Institute of Law and Economics (RILE) of the Erasmus School of Law; Louis Visscher is Associate Professor in Law and Economics at RILE.

1 We exclude fatal accidents from our analysis, because this requires different economic concepts (the so-called value of a statistical life and value of a statistical life year) than that applied in this paper. 
period of time or persist indefinitely. All these negative effects lead to a diminution of what could generally be described as quality of life.

The term 'pain and suffering damages' is often used by legal systems to denote the damages awarded to compensate for the pain, fear, anxiety, suffering, anguish and emotional distress experienced with a physical injury. Some legal systems also compensate for the loss of enjoyment of life as such, which is frequently termed as 'loss of amenity'. However, the most important aspect of a personal injury, namely the impact of the injury to the health condition itself, is usually neglected and not assessed at all. Yet it is this diminution in health that primarily affects the quality of life of an individual, which should be the basic element in evaluating injury-related losses. In this paper we do not use the term 'pain and suffering damages' in a strictly legal or literal sense. By 'pain and suffering damages' we denote all damages awarded to compensate for nonpecuniary losses resulting from an injury. We focus specifically on the diminution in the quality of life following from the injury and propose the use of insights from the field of health economics to allow an assessment of the negative effects visited upon the health condition of the injured individual.

The concept of Quality Adjusted Life Years (QALYs) from the domain of health economics addresses the impact of diverging health impairments on quality of life and is able to convey both the severity and the duration of a health impairment. In our opinion, it can offer a systematic external framework which allows a better assessment of pain and suffering damages in personal injuries than the current legal approach. This way, such damages can be founded on their true basis, that is, the impact of the personal injury on the quality of life of the victim. ${ }^{2}$

2 It is beyond the scope of our paper to address the issues related to using a regulatory measure like QALYs for the assessment of pain and suffering damages. We refer the interested reader to the following publications. CR Sunstein/E Posner, Dollars and Death (2005) 72 University of Chicago Law Review (UChi LRev) 537 discuss the possibility of using the value of statistical life, which is also developed in the area of regulation, for awarding damages in tort law. TR Miller, Willingness to Pay Comes of Age: Will the System Survive? (1989) 83 Northwestern University Law Review (NwU LRev) 876 analyses methods for valuating life, health and safety which were originally developed for use in regulatory analysis, but which have found their way into tort litigation as well. TR Miller, Valuing Nonfatal Quality of Life Losses with Quality-Adjusted Life Years: The Health Economist's Meow (2000) 13 Journal of Forensic Economics (JFE) 145 has also suggested to use QALYs as a technique that forensic experts can apply to help guide jury valuations on quality of life losses. Miller describes several existing QALY scales and argues that per case, depending on the injuries of the victim, different scales might be applied. Then, experts, by using the selected scale, have to evaluate the plaintiff's functional and psychological loss (by polling the plaintiff and possibly his caregivers and by examining existing surveys or even by surveying people similar to the victim) and subsequently convert it into QALY loss. Our paper differs from Miller's approach in the sense that we propose to use the general QALY weights as they can be found in health 
Our paper is structured as follows. In Section II we address the goals attributed to pain and suffering damages. According to the literature, the severity and duration of the health impairment forms the starting point for assessing pain and suffering damages. This holds not only for the legal literature that focuses on the goals of compensation and satisfaction, but also for the law and economics literature that highlights the goal of deterrence. In Section III we briefly describe the ways in which different European countries deal with pain and suffering damages. In Section IV we discuss the concept of QALYs, which expresses the gravity of different health conditions. This concept in our view provides important information regarding pain and suffering damages, precisely because it has regard to the severity and duration of health impairments. In Section V we will compare the magnitude of pain and suffering damages in concrete cases in different European countries with our theoretical findings. We will not reach an exact determination of the 'correct magnitude' of pain and suffering damages, because the existing research does not allow such a conclusion. What does become clear, however, is that the amounts that are awarded are generally too low. In Section VI, we give our conclusions.

\section{The goals of pain and suffering damages}

\section{A. Compensation and satisfaction as main goals}

If one reads the legal literature regarding the goals and functions of pain and suffering damages, it quickly becomes clear that two possible goals are especially emphasised, even though in practice they might not always be distinguishable: compensation and satisfaction. ${ }^{3}$ First and foremost, damages for non-pecuniary losses aim at compensating the victim. ${ }^{4}$ In this respect, they

economics literature, without estimating them in each and every individual case. The costs of doing so in our view would be very high. We also use a much lower monetary value for a QALY than Miller does, to reduce the risk of overestimating non-pecuniary losses. In our view, QALYs offer a good starting point in the assessment of pain and suffering damages, because they focus on the duration and intensity of the health impairment. However, courts should have the possibility to also include other relevant factors into the final assessment. Our paper leaves more room for this than Miller's more detailed approach does. Finally, we provide a comparison of the QALY-based approach with the outcome of concrete cases in several European countries.

3 See eg C van Dam, European Tort Law (2006) 301-303. It is noteworthy that King, in a paper which explicitly analyses the relationship between pain and suffering damages and the goals of tort law in general, argues for the abolition of pain and suffering damages because they are in his view incompatible with these goals. See JH King Jr, Pain and Suffering, Noneconomic Damages, and the Goals of Tort Law (2004) 57 Southern Methodist University Law Review (SMU LRev) 201.

4 See eg VE Schwartz, Pain and Suffering Damages: What Are They and Can They Be Measured ? in: L Kramer (ed), Reforming the Civil Justice System (1996) 425. 
serve the same goal as damages for pecuniary losses. Broadly stated, the idea is that the damages provide something positive to the victim which, as far as possible, offers some counterweight against the losses he has suffered. Comparative analysis of damages for non-pecuniary loss clearly shows that compensation is regarded as an important goal of pain and suffering damages in all countries. ${ }^{5}$

A second goal that is often distinguished is 'satisfaction', ie making up for or recognising the injustice that was done, or satisfying the victim's feelings of grievance or outrage. The term is sometimes directed more towards the injurer than the victim, and then it aims at 'letting the injurer pay'.

It is not in every legal system that satisfaction is regarded as a separate goal from compensation. In Austria, Belgium, Poland and Spain compensation is regarded as the sole goal. ${ }^{7}$ Regarding English law, it is doubted if satisfaction is relevant. ${ }^{8}$ In France, punishment was historically regarded as a goal, but since fault liability has increasingly been replaced by strict liability, this view no longer holds. Compensation of objective losses is a better explanation. Subjective perceptions are not relevant, because that cannot explain why comatose victims also receive compensation. ${ }^{9}$

In other countries, satisfaction is recognised as a separate goal. In Italy, compensation is recognised as the primary goal of the main head of pain and suffering damages in personal injury cases while satisfaction is a secondary function. ${ }^{10}$ In Dutch and Greek law, compensation and satisfaction may be regarded as the two most important functions. ${ }^{11}$ Regarding the Netherlands, recent literature shows that satisfaction is currently interpreted more as acknowledgment of sorrow. This is also how the Dutch Supreme Court has expressed it. ${ }^{12}$ The Dutch legislation is based on the German, which takes compensation (Ausgleich) and satisfaction (Genugtuung) as the main func-

5 WVH Rogers (ed), Damages for Non-Pecuniary Loss in a Comparative Perspective (2001).

6 See eg SD Lindenbergh, Smartengeld (Pain and Suffering Damages) (1998) 60.

7 E Karner/H Koziol, Austria, in: Rogers (fn 5) no 26 ff; H Cousy/D Droshout, Belgium, in: Rogers (fn 5) no 19 f; $M$ Nesterowicz/E Bagińska, Poland, in: Rogers (fn 5) no 2, $16 \mathrm{ff} ;$ M Martín-Casals/J Ribot/J Solé, Spain, in: Rogers (fn 5) no 1, $18 \mathrm{ff.}$

8 WVH Rogers, England, in: Rogers (fn 5) no 17.

$9 S$ Galand-Carval, France, in: Rogers (fn 5) no $30 \mathrm{ff}$.

10 FD Busnelli/G Comandé, Italy, in: BA Koch/H Koziol (eds), Compensation for Personal Injury in a Comparative Perspective (2003) no $10 \mathrm{ff}$.

11 MHWissink/WH van Boom, The Netherlands, in: Rogers (fn 5) no $18 \mathrm{ff} ;$ KD Kerameus, Greece, in: Rogers (fn 5) no 6 ff.

12 R-J Tjittes, Smartengeld voor bewustelozen (Pain and Suffering Damages for the Unconscious) [2003] Nederlands Tijdschrift voor Burgerlijk Recht (NTBR) 50. 
tions of pain and suffering damages. ${ }^{13}$ Compensation is the most important function, but satisfaction enables the incorporation of other factors in the determination of damages, such as the injurer's degree of fault. However, this only plays a minor role as compared to compensation objectives. ${ }^{14}$ Sometimes a third function is added in cases of severe injuries which lead to the total destruction of the victim's personality. In such cases, where compensation and satisfaction are not possible anymore, pain and suffering damages serve to express the importance German law attaches to human dignity. ${ }^{15}$

Lindenbergh argues that, in the Netherlands, satisfaction has no separate meaning besides compensation because factors such as the behaviour of the injurer can also be captured under the compensation analysis. ${ }^{16} \mathrm{Tjittes} \mathrm{reaches}$ the same conclusion if 'acknowledgment of sorrow' is used in a subjective way. However, if it is used in an objective way, so that it is irrelevant if the victim was aware of any suffering, it can lead to the award of pain and suffering damages where the mere compensation goal could not. After all, if someone is not aware that he has suffered, there is nothing to compensate. Tjittes regrets that the Dutch Supreme Court on this point did not provide the same level of clarity as the German and French Supreme Courts, which accept human dignity and the personal integrity of the victim as reasons for awarding pain and suffering damages in cases where the victim was unconscious or comatose. $^{17}$

In conclusion, compensation is generally regarded as a main goal of pain and suffering damages. Some countries regard satisfaction as a separate goal whereas others do not. In any case, the starting point for the assessment of pain and suffering damages always lies in the severity of the losses. Issues such as the degree of fault may have an impact, but this will be limited. Hence, for the assessment of damages, the nature, duration and intensity of the pain, the seriousness of the injury, the extent of the physical and psychological diminution in health, the loss of enjoyment of life, etc are of paramount

13 BS Markesinis/H Unberath, The German Law of Torts. A Comparative Treatise (4th edn 2002) $916 \mathrm{ff}$.

14 Lindenbergh (fn 6) 16, 18, 33. Also see eg J Luckey, Schmerzensgeld in Deutschland Tendenzen der Rechtsprechung, in: AG Rechtsanwälte im Medizinrecht eV (ed), Arzthaftungsrecht - Rechtspraxis und Perspektiven (2006) $51 \mathrm{ff}$.

$15 U$ Magnus/J Fedtke, Germany, in: Rogers (fn 5) no 9.

16 Lindenbergh (fn 6) 45. SD Lindenbergh, Smartengeld. Tien jaar later (Pain and Suffering Damages. Ten years later) (2008) 6 states that compensation also plays the central role in Germany and England.

17 Tjittes [2003] NTBR 51. Also see T Hartlief, Affectieschade: vergoeden of erkennen? De rol van het vermogensrecht bij het verwerken van leed van naasten (Loss of Affection: Compensate or Recognize? The Role of Patrimonial Law in Coping with the Suffering of Loved Ones), in: GE van Maanen (ed), De rol van het aansprakelijkheidsrecht bij de verwerking van persoonlijk leed (The Role of Tort Law in Coping with Personal Losses) (2003) 136. 
importance. Several authors argue that one should in principle strive for full compensation, however difficult. ${ }^{18}$ The fact that pain and suffering damages are often restricted is not because immaterial interests are of inferior quality, but because it is difficult to assess them in monetary terms. ${ }^{19}$

\section{B. Prevention as goal?}

The legal literature on the goals of tort law in general, and pain and suffering damages in particular, sometimes refers to prevention as a separate goal. ${ }^{20}$

The law and economics literature, which in the USA is incorporated into the legal literature generally, focuses on precisely this preventive goal. The basic idea is that the prospect of being held liable if one causes losses provides one with incentives to take care and/or to reduce one's activity level. In this literature, there is extensive discussion of the issue whether pain and suffering should be included in the damages. The so-called prevention theory argues that injurers should pay pain and suffering damages in order to receive the correct behavioural incentives. The so-called insurance theory, however, argues that the victim should not receive compensation for such losses, because rational actors would not take out insurance against them. We believe a synthesis of both theories can be achieved if one realises that rational people are willing to spend resources in trying to avoid accidents which might cause immaterial losses. These resources in our view form the correct basis for damages, under both the prevention theory and the insurance theory. ${ }^{21}$

We let this debate rest here, because it is not decisive for our paper. ${ }^{22}$ What is important is that if one accepts prevention as a separate goal of pain and

18 See eg Lindenbergh (fn 6) 60 and G Müller, Zum Ausgleich des immateriellen Schadens nach \847 BGB [1993] Versicherungsrecht (VersR) 911 who strongly emphasises the difficulties in measuring immaterial losses.

19 Lindenbergh (fn 6) 60; Müller [1993] VersR 911; Karner/Koziol (fn 7) no 3.

20 See eg KS Abraham, The forms and functions of Tort Law (2nd edn 2002) $15 \mathrm{f}$; W van Gerven/J Lever/P Larouche, Cases, Materials and Text on National, Supranational and International Tort Law (2000) $25 \mathrm{ff}$; Prosser and Keeton on the Law of Torts (5th edn 1984) 25; H Kötz, Deliktsrecht (9th rev edn 2001) $18 \mathrm{ff}$.

$21 R R$ Bovbjerg/FA Sloan/JF Blumstein, Valuing Life and Limb in Tort: Scheduling 'Pain and Suffering' (1989) 83 NwU LRev 913 fn 31; M Geistfeld, Placing a Price on Pain and Suffering: A Method for Helping Juries Determine Tort Damages for Nonmonetary Injuries (1995) 83 California Law Review (Cal LRev) 779; H-B Schäfer/C Ott, Lehrbuch der ökonomischen Analyse des Zivilrechts (4th rev edn 2005) 371.

22 We refer the interested reader to eg Bovbjerg/Sloan/Blumstein (1989) $83 \mathrm{NwU} \mathrm{LRev}$ 913; C Ott/H-B Schäfer, Schmerzensgeld bei Körperverletzungen. Eine ökonomische Analyse [1990] Juristenzeitung (JZ) 568; E Smith Pryor, The Tort Law Debate, Efficiency, and the Kingdom of the Ill: A Critique of the Insurance Theory of Compensation (1993) 79 Virginia Law Review (Va LRev) 110 ff; SP Croley/JD Hanson, The 
suffering damages, the magnitude of damages should again be based on the severity and duration of the injuries. After all, the prevention goal entails that the potential injurer should be confronted with the consequences of his behaviour for others. ${ }^{23}$ The consequences of the accident for the victim, besides his pecuniary losses, consist of the impact of the accident on his quality of life. Hence, the basis of damages is again found in the extent and duration of the health impairment.

\section{Conclusion}

Our conclusion of this Section can be brief. Compensation is generally regarded as the main goal of pain and suffering damages. Satisfaction is sometimes seen as an additional, separate goal, but often it is not. Regarding prevention, European legal literature seldom mentions it as a separate goal, but in the law and economics literature it is paramount.

It is not our aim to argue which of the possible goals is more important than the others. What is important for our paper is that proponents of all the abovediscussed goals state that pain and suffering damages must primarily be based on factors such as the nature, duration and intensity of the pain, the seriousness of the injury, etc. Issues such as the behaviour of the injurer may subsequently lead to slight corrections of the initially assessed amount.

Nonpecuniary Costs of Accidents: Pain-and-Suffering Damages in Tort Law (1995) 108 Harvard Law Review (Harv LRev) 1845 ff, 1898, 1906 ff; M Geistfeld (1995) 83 Cal LRev 779; J Arlen, Tort Damages, in: B Bouckaert/G de Geest (eds), Encyclopedia of Law and Economics, Vol II Civil Law and Economics (2000) 702; MG Faure, Compensation of Non-Pecuniary Loss: An Economic Perspective, in: U Magnus/J Spier (eds), European Tort Law, Liber Amicorum for Helmut Koziol (2000) 143; S Shavell, Foundations of Economic Analysis of Law (2004) 242 and 269 ff; Schäfer/Ott (fn 21) 371; SD Lindenbergh/PPM van Kippersluis, Non Pecuniary Losses, in: M Faure (ed), Tort Law and Economics, Encyclopedia of Law and Economics, Vol 1 (2009) $218 \mathrm{ff}$.

23 It should be noted that under a rule of negligence, damages do not necessarily have to equal the losses of the victim. As long as expected liability outweighs the cost of optimal care, the injurer will receive the correct care incentives. However, as long as it is clear for the potential injurer what constitutes due care, basing the damages on the losses will not lead to over-deterrence, because the potential injurer can escape liability by taking due care. Hence, basing damages on losses can provide the correct care incentives under both negligence and strict liability. Given that a claim for pain and suffering damages may be based on negligence in the one accident setting and on strict liability in the other, in our paper we do not further discuss this possible difference in damages between the two rules. Besides, if the legal system requires a causal relationship between the negligence and the losses, this difference between negligence and strict liability disappears so that damages should be based on the losses under negligence as well. See M Kahan, Causation and the Incentives to Take Care under the Negligence Rule (1989) 18 Journal of Legal Studies (JLS) 427. 
In our view, the concept of QALYs provides a very good starting point for assessing pain and suffering damages, because it has regard to the impact of the injury (with the associated pain, residual impairments, scars, etc) on the quality of life of the victim. Hence, it aims at precisely the immaterial aspects that pain and suffering damages seek to address. We therefore argue in the remainder of our paper that QALYs could be utilised as a way to yield better assessments of pain and suffering damages. Of course, after the initial assessment of pain and suffering damages on the basis of QALYs, subsequent corrections on the basis of other factors that are deemed relevant in a particular jurisdiction, such as the degree of fault of the wrongdoer, are still possible. The same holds for the possibility of attaching significance to specific circumstances of the individual case and the individual victim, which may justify further adjustment of the objectively assessed QALY loss. The approach we propose does not concern this phase of fine-tuning. QALYs are, after all, based on large-scale research rather than on separate cases. Individual characteristics, for example the circumstance that amputation of a finger may affect a musician more severely than a lawyer, are not included in the QALY. Hence, QALYs are not relevant in the stage of fine-tuning. We will argue, however, that they could be used for a better first assessment of pain and suffering damages, which subsequently may be corrected on the basis of other factors.

\section{Assessment of pain and suffering damages in different countries}

\section{A. Introduction}

To attain the aforementioned goals of compensation, satisfaction and prevention, it is evident that court awards for pain and suffering damages should correspond to the harm incurred. In personal injury cases especially, this consequently entails that the assessment of pain and suffering damages should involve not only the incorporation of all immaterial losses incurred in the compensation award but also the calculation of the damages in the light of criteria such as the duration and intensity of the pain, the severity of the injury, the reduction in physical and psychological aspects of health, as well as the loss of enjoyment of life and emotional strain normally associated with the specific injury. Different countries recognise these criteria explicitly or implicitly as determinants for the evaluation of pain and suffering damages. In some countries this is also evident in the categorisation of personal injury case law in tables according to the injury suffered. ${ }^{24}$ However, the ways these criteria are employed to assess pain and suffering damages in personal injury cases, and the size of the awards that they produce, differ within and between legal

24 See for instance S Hacks/A Ring/P Böhm, Schmerzensgeld-Beträge 2009 (26th edn 09/ 2008). 
jurisdictions. ${ }^{25}$ The mere fact that the amounts differ between jurisdictions, although often stressed in the literature, is not in itself problematic. After all, differences in, for instance, Gross National Income Per Capita, the level of social security, social norms, and the existence of public and/or private insurance, all may impact on the assessment of the immaterial losses connected with the injuries. Differences within a jurisdiction in our view are more difficult to justify and may be caused by the lack of a coherent framework for assessment.

\section{B. Tables, tariffs and judicial discretion}

Utilising tables and tariffs to assess pain and suffering damages facilitates the standardisation of awards within a country and allows inter-country comparisons. However, their use should be distinguished according to the type of tables and tariffs used and the level of courts' adherence to them in their decision on pain and suffering damages.

In Germany and the Netherlands, systematised tables exist which record the material facts and amounts awarded in previously adjudicated personal injury cases. In Germany, the so-called Schmerzensgeldtabellen are tables of pain and suffering damages awarded in previous cases which assist courts in determining damages in the case at hand. Even though judges are expected to consult these tables and award an amount comparable to what was previously awarded for a similar injury, they still enjoy a wide discretion and may decide to award amounts of different magnitude provided they give adequate reasons to justify their decision. ${ }^{26} \mathrm{~A}$ certain amount of discretion is also enjoyed by courts in the Netherlands. An overview of cases published by the journal Verkeersrecht with damages awarded for pain and suffering in previous cases serves as a guideline, while courts may also take into consideration amounts awarded in other countries. ${ }^{27}$ The resulting awards of pain and suffering damages are considered to be quite modest compared to other legal systems.

Italy is an interesting case as the tables used for the evaluation of pain and suffering damages in personal injury cases do not consist of previously decided cases and the amounts there awarded but of amounts corresponding to so-

25 For extensive overviews, see Rogers (fn 5); Koch/Koziol (fn 10); G Comandé, Towards a Global Model for Adjudicating Personal Injury Damages: Bridging Europe and the United States (2005) 19 Temple International and Comparative Law Journal (Temp Int'l \& Comp LJ) 247.

26 B Markesinis/M Coester/G Alpa/A Ullstein, Compensation for Personal Injury in English, German and Italian Law. A Comparative Outline (2005) 59-82; Markesinis/ Unberath (fn 13) 919-923.

27 Wissink/van Boom (fn 11) no 43 ff; WH van Boom, The Netherlands, in: Koch/Koziol (fn 10) no 66 ff; SD Lindenbergh/R Verburg, The Netherlands, in: M Bona/P Mead (eds), Personal Injury Compensation in Europe (2003) 373. 
called invalidity points. In Italy, immaterial losses in personal injury cases are divided in temporary and permanent damage to health (danno alla salute or danno biologico) and damages for moral suffering (danno morale). Damages to health are the most important and are always awarded in personal injury cases. Their calculation is facilitated by the use of tables drafted with the help of medical experts which indicate damages for each accruing invalidity point. ${ }^{28}$ Every court possesses its own table which may result in systematically diverging amounts of compensation in different Italian jurisdictions. For this reason the legislator has intervened with a law that fixes uniform damages tables for the first nine percentage points of invalidity, leaving damages for more serious cases to be determined by the courts. ${ }^{29}$ The calculation of damages for moral suffering is left to the discretion of the court, although in practice the amount awarded is roughly half the amount of damages to health. ${ }^{30}$

In Belgium, experts evaluate the injury suffered by assigning to it a percentage of invalidity. This percentage is thought to reflect the degree of inability to work. ${ }^{31}$ Unlike Italy, where damage to health as such automatically results in compensation, personal injury is compensated in Belgium on the basis of its relation to the degree of the victim's inability to work following the injury. A table known as the Indicatieve tabel van forfaitaire schadevergoedingen bij verkeersongevallen contains compensation amounts per invalidity percentage for personal injuries as well as compensation amounts for other kinds of losses. ${ }^{32}$ The amounts specified in the table are only a guideline for the courts.

In England, the relative magnitude of pain and suffering damages for different personal injuries is set by judges and moderated by the Court of Appeal. ${ }^{33}$ The most severe personal injury is awarded an amount of pain and suffering damages which is considered as the point of reference for all other injuries. ${ }^{34}$ Scaling down from that amount, tariffs for other injuries are created. These tariffs do not provide concrete amounts but usually allow for a range for the same category of injuries, leaving it to the discretion of the judge to grant an amount within this range that varies according to the circumstances of the case.

28 Markesinis/Coester/Alpa/Ullstein (fn 26) 82-96, FD Busnelli/G Comandé, Italy, in: Rogers (fn 5) no $1 \mathrm{ff}$.

29 See <www.altalex.com/index.php?idnot $=3970>$ for the currently set amounts of damages to health up to $9 \%$ points of invalidity as updated by Decree of the Ministry of Economic Development of 9 June 2009.

30 See supra fn 25.

31 Cousy/Droshout (fn 7) no $11 \mathrm{ff}$.

32 H Cousy/D Droshout, Belgium, in: Koch/Koziol (fn 10) no $71 \mathrm{ff}$.

33 Markesinis/Coester/Alpa/Ullstein (fn 26) 46-51; Van Dam (fn 3) 323.

34 WVH Rogers, England, in: U Magnus (ed), Unification of Tort Law: Damages (2001) no $26 \mathrm{ff}$. 
Pain and suffering damages awarded in England are higher than those awarded in most EU countries.

In Austria judicial tariffs assign a monetary value to the pain and suffering experienced daily. The values differ depending on whether the pain was mild, medium, intense or extreme. ${ }^{35}$ These tariffs are frequently used by courts in the calculation of pain and suffering damages, although they are of limited importance for more serious and lasting injuries. ${ }^{36}$

Wide judicial discretion is characteristic of the assessment of pain and suffering damages in personal injury cases in Greece. Although the judge is expected to take past rulings into consideration, the lack of systematised tables or tariffs in practice results in decisions based only on the merits of the case. The resulting awards are rather low. ${ }^{37}$

\section{In need of an alternative assessment method?}

In all these legal systems, the intensity of the pain, the type, severity and duration of the injury, the reduction in health, etc are supposed to play a major role in the calculation of pain and suffering damages. However, pain and suffering damages for similar or even the same injuries differ greatly not only between but also within countries. The latter consideration in particular suggests that pain and suffering damages awarded may not be calculated correctly in accordance with the severity and duration of the health impairment. Courts seem to lack a measure against which the correctness of the awards can be evaluated. In Germany and the Netherlands, the use of tables with previously adjudicated amounts to facilitate the assessment of pain and suffering damages does not necessarily result in amounts based on the extent of the injury. After all, reliance on past rulings does not necessarily mean that these rulings were correct to start with. In England, the existing tariffs are based on the courts' perception of the injuries and there is no reason why pain and suffering damages for the gravest injury, used as the reference point for all other awards, should be assessed at current levels instead of an order of magnitude higher or lower. In Italy, where specialised invalidity tables exist, the problem remains that pain and suffering damages for the same serious injuries may differ systematically within the country's jurisdictions. In Belgium and Austria, where the tables and tariffs are at most a recommendation to the courts, the problem again arises how pain and suffering damages are to be evaluated. In Greece, total judicial discretion creates reasonable

35 I Greiter, Austria, in: Bona/Mead (fn 27) 31.

36 BA Koch/H Koziol, Österreich, in: Koch/Koziol (fn 10) no 60 ff; Karner/Koziol (fn 7) no $20 \mathrm{ff}$. Indicative tariffs may be found in Judicial Studies Board, Guidelines for the Assessment of General Damages in Personal Injury Cases (9th edn 2008).

37 Kerameus (fn 11) no 7. 
doubt about the criteria used to evaluate losses and the resulting magnitude of pain and suffering damages.

Different methodologies employed in the assessment of damages, resulting in highly divergent amounts, suggest that the existing legal frameworks are inadequate to effect the proper assessment of pain and suffering damages. In the remainder of our paper we will argue that the concept of Quality Adjusted Life Years offers a good reference point on the basis of which to reach relative rankings of different health conditions resulting from accidents.

\section{Quality Adjusted Life Years}

\section{A. What are QALYs?}

A QALY is a measure of the value of living one year in a certain health condition. The health condition is used as a proxy for quality of life during the year. QALYs are often used in evaluating different health programmes, medical treatments and techniques. ${ }^{38}$

In order to be able to calculate QALYs, different health conditions have to be established, ranging from perfect health to death and including everything in between. Each condition is assigned a QALY weight, varying from 0.00 (death) to 1.00 (perfect health). Conditions which are regarded as even worse than death are assigned a negative value. QALYs are calculated as the sum of the health conditions of the individual during the time those conditions last. By applying QALYs, one can form an opinion on the relative value of different treatment possibilities. Suppose for example that, for a person with a certain ailment two treatments exist which are equally expensive. Treatment $\mathrm{A}$ increases the quality of life by 0.1 for 5 years, treatment $B$ by 0.2 for 3 years. According to the QALY method, treatment $B$ is preferred, because it yields 0.6 QALY (0.2 X 3) while treatment A 'only' yields 0.5 QALY for the same amount of money. ${ }^{39}$

38 See eg J Brazier et al, A review of the use of health status measures in economic evaluation (1999) 3 Health Technology Assessment (HTA) 3, 4; P Dolan, The measurement of health related quality of life for use in resource allocation decisions in health care, in: AJ Culyer/JP Newhouse (eds), Handbook of Health Economics, vol 1B (2000); $S$ Folland/AC Goodman/M Stano, The Economics of Health and Health Care (5th edn 2007) 81.

39 This comparison does not yet show whether treatment A and/or B are worth their costs. For this, one has to evaluate how much a QALY is worth in money terms. See further Section IV.B. below. 
Different methods exist for trying to establish QALY weights. ${ }^{40}$ In some methods, respondents are asked to compare two situations in order to elicit their overall perception of a specific ailment. In the 'standard gamble' method, for example, people are asked to choose between living in a certain health condition on the one hand, and on the other hand, undergoing treatment which, with varying probability, leads to either perfect health or death. The lowest probability of perfect health which the respondents still assess as high enough to undergo the treatment determines the QALY weight of the ailment. If, for instance, I am indifferent between continuing to live with the ailment in question or undergoing a treatment which has $70 \%$ probability of restoring me to perfect health and $30 \%$ probability of leading to death, then the QALY weight of the ailment is 0.7. Under another method, the 'time trade-off', respondents are asked to trade off $x$ years of perfect health with $y$ years with a certain health condition. The ratio $x / y$ determines the QALY weight. Hence, the more life-years the respondent is willing to forego in order to achieve perfect health, the lower the QALY weight for the health condition involved. So, if a respondent assesses 40 years life expectancy with the ailment as equal to 30 years in perfect health, the QALY factor is 0.75 . In the 'person trade-off', respondents are asked to make a trade-off between people in one health condition and people in another. Respondents are, for example, asked to choose between improving the health or extending the life expectancy of $x$ people in the first (better) condition and improving the health or extending the life expectancy of $y$ people in the second (worse) condition. ${ }^{41}$ The ratio $x / y$ determines the relative QALY weights of both conditions. If respondents are, for example, indifferent between extending life by one year for 20 healthy people and extending life by the same amount for 25 people with a certain health condition, then the QALY weight of the second health condition is 20/ $25=0.8$.

In another method, the 'visual analogue scale', respondents are asked to rank the ailment on a vertical line with concrete endpoints ranging from 0 to 100 where 0 represents death and 100 represents perfect health. To account for ailments that may be perceived as worse than death, the endpoints of the scale may be modified so that 0 represents the worst imaginable health condition

40 See eg $E$ Nord, Methods for quality adjustment of life years (1992) 34 Social Science and Medicine (Soc Sci Med) $561 \mathrm{ff} ; M$ Johannesson/B Jönsson/G Karlsson, Outcome Measurement in Economic Evaluation (1996) 5 Health Economics (Health Econ) $283 \mathrm{f} ; H$ Bleichrodt/M Johannesson, Standard gamble, time trade-off and rating scale: experimental results on the ranking properties of QALYs (1997) 16 Journal of Health Economics (J Health Econ) 155-157; Brazier et al (1999) 3 HTA 23 ff; Dolan (fn 38) $1733 \mathrm{ff}$; US EPA, Office of Research and Development, Human Health Metrics for Environmental Decision Support Tools: Lessons from Health Economics and Decision Analysis (Sept 2001) 16, 17; JK Hammitt, QALYs Versus WTP (2002) 22 Risk Analysis 994-996 for a more extensive treatment.

41 JK Hammitt (2002) 22 Risk Analysis 995. See also US EPA (fn 40) 17. 
and 100 represents the best imaginable health condition. For example, an ailment rated with 85 points on the scale has a QALY factor of 0.85 .

Other ways used to establish QALY weights are frequently referred to as 'generic' or 'quality of life' measures as they measure general attributes of health conditions without emphasising a particular ailment. One of these measures, the EuroQoL EQ-5D ${ }^{42}$ questionnaire, differentiates health states using five dimensions: mobility, self care, usual activities, pain/discomfort and anxiety/depression. In the first part of the questionnaire, respondents are asked to mark their health condition on the basis of these five dimensions by indicating whether they have no problems, moderate problems or extreme problems in each. Each of these levels is assigned a weight previously elicited by the visual analogue scale or the time trade-off method. In the second part of the questionnaire, respondents are asked to rank their health condition on a visual analogue scale, thus communicating their overall perception of the ailment. The possible combinations of dimensions and their levels yield in total 243 different health states to which death and unconsciousness are added. The QALY weight for a given health state is calculated from the respondent's overall evaluation of all health dimensions by adding together the relevant weights and subtracting them from 1.00 , ie perfect health.

Another generic measure, the 'Health Utilities Index Mark 3' (HUI3), ${ }^{43}$ uses eight dimensions to classify health states: vision, hearing, speech, ambulation, dexterity, emotion, cognition and pain. Each dimension comprises five or six different levels (speech, emotion and pain have five levels) indicative of a gradual deterioration in that dimension. These levels are assigned a weight previously elicited by standard gamble and visual analogue scale methods. Combining all possible dimensions and levels, 972,000 health states can be realised in total. Respondents are asked to indicate how much a certain condition affects the various health dimensions. The QALY weight of the health state reflects the respondent's overall evaluation of all health dimensions.

Other generic measures to elicit QALY weights are the 'Quality of Well-Being Scale', the 'SF-6D', the '15D' and the 'Rosser disability/distress scale'. However, so far the EQ-5D and the HUI3 are regarded as better measures for the QALY weight elicitation. ${ }^{44}$

42 See $<$ www.euroqol.org $>$ and especially $K$ Cheung/M Oemar/M Oppe/R Rabin, EQ5D User Guide Basic information on how to use EQ-5D, $2009<$ www.euroqol.org/ fileadmin/user_upload/Documenten/PDF/User_Guide_v2_March_2009.pdf $>$.

43 See $<$ www.fhs.mcmaster.ca/hug/hui3.htm $>$. See also J Horsman/W Furlong/D Feeny/ $G$ Torrance, The Health Utilities Index (HUI $\left.{ }^{\circledast}\right)$ : concepts, measurement properties and applications (2003) 1 Health and Quality of Life Outcomes (HQLO) $<$ www.hqlo.com/ content $/ 1 / 1 / 54>$. HUI3 is the most recently developed Health Utilities Index. Previous versions are HUI, HUI1 and HUI2.

44 See Brazier et al (1999) 3 HTA 76. 
The different methods lead to different results, due amongst other things to the type of questions being asked and the comparison being made (with death, perfect health or another health condition). The standard gamble, the time trade-off and the person trade-off are methods that require respondents to compare two different situations on the basis of health (un)certainty, the duration of different health conditions and the health of other people respectively, whereas the visual analogue scale asks for an overall evaluation of a particular health state by drawing a mark on a line, tasks which may be difficult for respondents to understand and perform. On the other hand, the generic measures in the form of a questionnaire are easier to understand but, since they classify health states on the basis of specified dimensions, there may be other affected aspects of health conditions that they are unable to evaluate. Furthermore it is relevant whether the questions are asked to people who actually have the health condition or not, or to doctors or other health specialists. Depending on who answers the questions, the results may again be different. If people with the condition are judged as more competent for the elicitation of QALY weights, the question then becomes when to ask them. People can adapt themselves to their life circumstances and thus an evaluation of health condition made when this is first incurred may be different from an evaluation at a later time. ${ }^{45}$ Hence, much research is still needed and a refinement of the methods employed is necessary in order to acquire more uniform QALY weights for the range of different health conditions.

\section{B. Pain and suffering damages based on QALYs}

Notwithstanding the abovementioned problems, we think that the insights that have been acquired in health economics are of great value for the topic of pain and suffering damages. Obviously the results have to be handled with care due to the problems discussed above. However, in our view, even with the limitations that still exist, it is better to base damages awards for deteriorations in health on the results of this specialised research than on the amounts that courts have awarded in the past. After all, there is no reason to assume in advance that these judgments approximate the amounts which would do justice to the gravity of the immaterial loss.

On the basis of the extensive health economics literature in which assessments of QALY gains of different treatments and medical interventions are made, educated assessments of the average QALY loss due to impairments in health can be made. By subsequently attaching a money value to a QALY, pain and suffering damages may be determined. ${ }^{46}$ This can be done by evaluating

45 Dolan (fn 38) 1738, 1739.

46 See eg M Johannesson/MC Weinstein, On the decision rules of cost-effectiveness analysis (1993) 12 J Health Econ 466; H Bleichrodt/J Quiggin, Life-cycle preferences over 
alternative treatments in terms of the QALYs they generate and the costs to be implemented. By comparing the costs of the health treatments per QALY gained, one arrives at a potential money value for one QALY. Another way is to calculate the willingness to pay for a QALY increase. A recent overview of literature which attaches a money value to a $\mathrm{QALY}^{47}$ indicates that authors who have calculated the willingness to pay for a QALY reach a value of about $€ 100,000$ to $€ 150,000$. Others look for the limits below or above which an additional QALY is worth or not worth its costs, and arrive at an upper limit of about $€ 184,000$. The famous 'kidney dialysis value', which is based on the consideration that kidney dialysis is regarded as a method which is (more than) worth its costs, gives a lower limit of about $€ 79,500$ to $€ 102,000$ for one QALY. In the UK, the National Institute for Clinical Excellence (NICE) uses a lower limit of about $€ 32,500$ to $€ 48,500$, which in most of the literature is regarded as too low. ${ }^{48}$ In an international overview from 2000, an amount of $€ 306,000$ is given as the median value of the different estimates ( 28 of the 35 estimates exceed $€ 113,000){ }^{49}$

\section{Magnitude of pain and suffering damages: legal and economic standards compared}

\section{A. Legal and economic standards}

As we have already mentioned above, several distinct factors are relevant in determining the magnitude of pain and suffering damages, such as the nature, duration and intensity of pain, grief and lost enjoyment of life, decreased life expectancy, residual impairments, psychological problems, etc. The nature

consumption and health: when is cost-effectiveness analysis equivalent to cost-benefit analysis? (1999) $18 \mathrm{~J}$ Health Econ $683 \mathrm{ff} ; P$ Dolan/R Edlin, Is it really possible to build a bridge between cost-benefit analysis and cost-effectiveness analysis? (2002) $21 \mathrm{~J} \mathrm{Health}$ Econ 828; T Klose, A utility-theoretic model for QALYs and willingness to pay (2003) 12 Health Econ $17 \mathrm{ff}$. Also see the EuroVaQ project which aims at developing robust methods to determine the monetary value of a QALY across a number of European States: <http://research.ncl.ac.uk/eurovaq/index.html>.

47 D Kenkel, WTP- and QALY-Based Approaches to Valuing Health for Policy: Common Ground and Disputed Territory (2006) 34 Environmental \& Resource Economics (Environ Resource Econ) 421. All amounts in Section IV.B. are expressed in Euros from 2008.

$48 M$ Pomp/W Brouwer/F Rutten, QALY-tijd. Nieuwe medische technologie, kosteneffectiviteit en richtlijnen (QALY-ty. New Medical Technology, Cost-Effectiveness and Guidelines) 37. <www.cpb.nl/nl/pub/cpbreeksen/document/152/doc152.pdf $>$. See p 39 for other research that yields low values.

49 RA Hirth/ME Chernew/E Miller/M Fendrick/WG Weissert, Willingness to Pay for a Quality-adjusted Life Year: In Search of a Standard (2000) 20 Medical Decision Making (Med Decis Making) 338, 340. 
and extent of the injuries have an especially large influence on the final quantification. ${ }^{50}$ Therefore QALYs, where the type of health impairment determines the QALY weight, in our view provide a good basis on which to determine pain and suffering damages. After all, the more serious the health impairment, the lower the QALY level of the victim will be, and the longer the health impairment lasts, the higher the total QALY loss suffered by the victim. Furthermore, this measure exactly expresses the non-pecuniary losses because it has regard to quality of life. Hence, the resulting awards are exclusive of any additional pecuniary losses.

The size of pain and suffering damages differs between countries. In the Netherlands, for example, the damages awarded are often lower than in other European countries ${ }^{51}$ and the United States. ${ }^{52}$ The highest amount in the Netherlands was about $€ 192,000$, in Germany $€ 614,000$, in Italy $€ 1,024,000$, and in England $€ 330,000$, though in Sweden it was $€ 122,000$ and in Denmark $€ 88,500 .^{53}$ As already mentioned, the mere fact that the amounts differ between countries may not be a problem in itself and may be explained by other factors. However, we doubt if such factors are also able to explain why the differences are so large. The lack of a systematic framework for assessing pain and suffering damages in our view may have contributed to these differences. The question of the correct quantification of pain and suffering damages cannot in any case be answered by merely comparing the amounts granted in different countries, because that method lacks an external yardstick. In order to answer the question, we therefore use the insights developed in Section IV and compare those insights with a number of concrete cases from different countries. ${ }^{54}$

In the current Section we provide information on the amounts of pain and suffering damages that were granted for a number of specific injuries in several European countries. Subsequently we compare these amounts with insights from the field of health economics, where QALY weights for the selected

50 Lindenbergh (fn 6) $235 \mathrm{ff}$. The same shows from Rogers (fn 5), Comandé (2005) 19 Temp Int'l \& Comp LJ $260 \mathrm{ff}$ and L Jaeger/J Luckey, Schmerzensgeld (4th edn 2008) $212 \mathrm{ff}$.

51 See SD Lindenbergh, Smartengeld: ontwikkeling en stilstand (Pain and Suffering Damages: Development and Stand-Still), in: M Jansen, Smartengeld (Pain and Suffering Damages) (2006) 10.

52 A Sebok, Translating the Immeasurable: Thinking About Pain and Suffering Comparatively (2006) 55 DePaul Law Review (DePaul LRev) 392; SD Sugarman, A Comparative Law Look at Pain and Suffering Awards (2006) 55 DePaul LRev 418.

53 For the Italian and German amounts, see Section V.B.1) below. The other amounts are derived from Jansen (fn 51) 10. All amounts are expressed in Euros from 2005/2006.

54 Utilising the insights from health economics in our view solves the issue discussed by Rogers (fn 5) 248 that 'damages for non-pecuniary losses are certainly arbitrary in the sense that it is difficult to find a logical basis on which damages for quadriplegia should be $€ 300,000$ rather than, say, $€ 30,000$ or $€ 3,000,000$ '. For a similar argument, see Comandé (2005) 19 Temp Int'l \& Comp LJ 301 ff. 
medical conditions are assessed. The health economics research in this area is extensive. We have chosen to use only publications which receive a quality score of at least 4.5 on a scale ranging from 1.0 to 7.0 (indicating lowest and highest quality respectively) as assessed by the Cost-Effectiveness Analysis Registry (CEA) of the Center for the Evaluation of Value and Risk in Health in Tufts Medical Center. ${ }^{55}$

It is important to note that, in the health economics literature, the passage of time is relevant. Costs of medical treatment may be incurred today while the benefits only occur in the future. Furthermore, the costs of medical treatment may recur over a certain period. Because of this time aspect, costs and benefits are discounted. Often the studies contain a sensitivity analysis using different discount rates to evaluate the exact influence of the discount factor. ${ }^{56}$ As far as we know, there is no common opinion on the 'correct' discount factor in health economics research. In practice, a discount factor of about 3-5\% is often applied. ${ }^{57}$ It is undisputed that the costs of medical treatment should be discounted, because spending a sum of money comes at the opportunity cost of investing it and receiving a return. There has been discussion, however, whether benefits realised in the future should also be discounted, because they do not relate to money which can be invested, but rather increases in quality of life. However, in order to account for the time preference, benefits should also be discounted, but not necessarily by the same factor as costs. ${ }^{58}$ The NICE in previous guidelines applied a discount factor of $6 \%$ for costs and $1.5 \%$ for health benefits. In a more recent version of the guidelines, both rates were set at $3.5 \%$. According to Brouwer et al., this is wrong, because it does not allow for the fact that the monetary value of health effects is expected to grow over time. They therefore argue that the discount factor for health effects should be lower than the discount factor for costs. ${ }^{59}$

Be this as it may, for the purposes of our paper, a different type of discounting is necessary. We will use the insights from the health economics literature regarding the impact of medical conditions on quality of life. This way, we assess the non-pecuniary loss caused by personal injuries. By relating this to a monetary value for a QALY, we derive a monetary expression of the nonpecuniary loss. After having done so, we still have to account for the duration of the medical condition. For example, if the monetary value of a certain injury amounts to $€ 10,000$ per year over a period of ten years, the damages should not simply be assessed at $€ 100,000$ but at the net present value of ten annual future payments of $€ 10,000$. The exact outcome depends on the discount factor

55 See $<$ https://research.tufts-nemc.org/cear/default.aspx $>$.

56 See eg DJ Torgerson/J Raftery, Discounting [1999] British Medical Journal (BMJ) 915.

57 WBF Brouwer et al, Need for differential discounting of costs and health effects in cost effectiveness analyses [2005] BMJ 446.

58 Torgerson/Raftery [1999] BMJ 915.

59 Browwer et al [2005] BMJ 447. 
applied. A discount factor of $4 \%$ would result in a lump sum payment of $€ 84,353$ while a discount factor of $6 \%$ would lead to $€ 78,017$. In this paper, we will apply a discount factor of $4 \%$, which is higher than the rate of $2.5 \%$ set in the United Kingdom ${ }^{60}$ and the $3.5 \%$ suggested by NICE. Weir et al argue that, for Canada, a discount factor of a maximum of $3 \%$ should be applied ${ }^{61}$ In our view, choosing a discount factor of $4 \%$ avoids the risk of overestimating the monetary value of non-pecuniary losses due to inadequate discounting.

\section{B. Concrete cases}

In this Section we will compare the amounts of pain and suffering damages which were awarded in concrete cases for four types of losses, with the amounts which result from applying the QALY approach. The selection of countries is made on the basis of the availability of comparable cases. The overview of amounts in different countries serves as an illustration of how the QALY approach compares to the legal outcome in those countries.

\section{1) Spinal cord lesion/paralysis}

In cases of spinal cord lesion in the Netherlands, damages in the amount of $€ 70,000$ to $€ 124,000$ are granted, depending on the position of the lesion, residual pain, possible influence on fertility, incontinence, etc. ${ }^{62}$ In a Dutch case from 1999, the Appellate Court granted $€ 90,756$ in pain and suffering damages to a 25-year-old victim who was paralysed in an accident due to a spinal cord lesion. Expressed in 2006 values, this would be $€ 111,630 .{ }^{63} \mathrm{In}$ Germany, a 25-year-old man who suffered a spinal cord lesion in an accident for which he was one-third comparatively negligent received $€ 150,000 .{ }^{64} \mathrm{In}$ another German case, the court awarded $€ 200,000$ to a victim who was paralysed from the neck down due to a spinal cord lesion. In other cases, even higher amounts were awarded..$^{65}$ The highest German award of pain and suffering damages ( $€$ 614,000), as already mentioned, was in respect of a high spinal cord lesion of a 3.5-year-old boy who cannot breathe on his own anymore, suffers from residual pain and also sustained other injuries. In Greece, $€ 250,000$ was granted to a 23 -year-old woman who suffered from

60 See Damages (Personal Injury) Order 2001, Statutory Instrument (SI) 2001/2301 $<$ www.opsi.gov.uk/si/si2001/20012301.htm>.

61 L Weir et al, The Discount Rate Revisited (Spring 2008) (13) Expert Witness newsletter 2008, <www.economica.ca/ew13_1p1.htm>.

62 Jansen (fn 51) $114 \mathrm{ff}$. The amounts are expressed in Euros from 2006.

63 Ibid, 116.

64 Jaeger/Luckey (fn 50) 1067.

65 Ibid, $1068 \mathrm{ff}$. 
quadriplegia due to a spinal cord lesion. ${ }^{66}$ In another Greek case, the court awarded $€ 128,000$ to a 25 -year-old man who was found $40 \%$ comparatively negligent for the accident that resulted in his paralysis due to a spinal cord lesion. ${ }^{67}$ In Italy the amount of $€ 1,024,128$ was awarded to an 18 -year-old victim who was rendered paralysed due to a spinal cord lesion after a car accident. ${ }^{68}$ The victim's young age and the severity of the injury $(85 \%$ paralysis) increased the damages award.

In a publication from 1999, a cost-effectiveness study regarding Computed Tomography (CT) scans for trauma patients was published. Major trauma patients arriving at a trauma centre are assumed to have unstable cervical spine injuries, until proven differently. In order to establish if this type of injury indeed exists, the standard procedure is a radiographic scan, which does not, however, always show the injury. The more expensive CT scan provides better information. The article investigates whether the better results of the CT scan are worth the costs. ${ }^{69}$ The utility adjustments caused by spinal injury are estimated with the use of the HUI2. The QALY weight of paralysis is assessed at 0.516 (ranging from 0.465 to 0.611$)^{70}$

Assuming non-perfect health before the paralysis, for example a QALY weight of 0.9, the decrease due to the paralysis is $0.384(0.9-0.516)$. If we apply a conservative monetary valuation of a QALY of $€ 50,000,{ }^{71}$ which is lower than the amounts proposed in the literature we discussed in Section IV.B., pain and suffering damages can be calculated as follows. Every year, the paralysis has lowered the quality of life of the victim by 0.384 QALY, which in monetary terms equals $€ 19,200$ ( $0.384 \mathrm{X} € 50,000)$. Assuming an average life expectancy of 78 years, a 25 -year-old victim has 54 years of remaining life expectancy. The pain and suffering damages hence are calculated as the net present value of 54 payments of $€ 19,200$, which amounts to $€ 439,000$. This is

66 Kalamata Court of First Instance 107/2003, online in NOMOS: <http://lawdb.intra softnet.com/index.php $>$.

67 Leukada Court of First Instance 472/2004, online in NOMOS: <http://lawdb.intra softnet.com/index.php $>$.

68 Savona Court of First Instance, 29 July 2005, online in De Jure: $<$ http://dejure.giuffre. it/psixsite/PaginePubbliche/default.aspx $>$.

69 CC Blackmore et al, Cervical Spine Screening with CT in Trauma Patients: A Costeffectiveness Analysis [1999] Radiology 117.

70 Ibid, 121, 122. As to HUI2, see fn 43 above.

71 We have chosen to apply this low estimate of $€ 50,000$ to reduce the risk of overestimating pain and suffering damages. As will become apparent in the remainder of the paper, the calculated amounts are already (much) higher than the amounts currently awarded in most countries. Given the possible problems in applying monetized QALY values in tort law, which we discuss in the text above, we want to avoid the possible risk of overestimated damages. By applying a very low estimate of $€ 50,000$, our proposal to substantially increase pain and suffering damages cannot be rejected by merely arguing that we have chosen too high a money value for a QALY. 
substantially higher than the amounts generally awarded by the Dutch, German and Greek courts. ${ }^{72}$ The highest German award is well in line with the proposed approach, however, if one takes into consideration that the victim there was even younger and that we use a low monetary value of $€ 50,000$. The Italian award in our view seems too high.

It is in principle possible to apply different monetary values to QALYs in different countries, to account for divergences in the general standard of living and other relevant factors. It goes beyond the scope of our paper to propose such monetary values for QALYs per country. However, the EuroVaQ project (see fn 46) will produce different monetary values for a number of European countries, enabling this further fine-tuning.

\section{2) Loss of an eye}

Pain and suffering damages for the loss of an eye differ greatly between countries. In the Netherlands awards are about $€ 22,000$. Italy and Greece make the highest awards ( $€ 80,000$ and $€ 88,000$ respectively), Austria the lowest $(€ 14,500) \cdot{ }^{73}$ However, the awards differ greatly from case to case. For example, in Germany a woman who suffered from inflammation of the cerebral membrane due to her contact lenses and was blinded in one eye received $€ 20,000$ in pain and suffering damages. ${ }^{74}$ On the other hand, a 12year-old boy lost an eye in an accident in which he was found comparatively negligent for one-third and he received $€ 125,000$. The fact that he lost an eye at such a young age, which forced him to be constantly careful in order to protect his remaining eye, increased the award..$^{75}$ In Greece, a 43-year-old mother of two received about $€ 88,000$ in pain and suffering damages for the complete loss of vision in her left eye. ${ }^{76}$ In another case, $€ 80,000$ was awarded to a 36year-old man who was injured in one eye by a flare and lost $80 \%$ of his vision $^{77}$. However, a 46-year-old man whose left eye was destroyed after someone kicked him in the face only received about $€ 29,000$. $^{78}$

72 If one also wants to incorporate a normal and expected worsening of health over time, the QALY decrease in later years will be lower, resulting in a lower final amount.

73 For Italy and Austria, see Lindenbergh (fn 51) 10. For Greece, see the published court decisions online in NOMOS: < http://lawdb.intrasoftnet.com/index.php >.

74 Jaeger/Luckey (fn 50) 411.

75 Ibid, 423.

76 Simvoulio tis Epikratias (Council of State) 2739/2007, online in NOMOS: < http:// lawdb.intrasoftnet.com/index.php $>$.

77 Athens Administrative Court of First Instance 3441/2006, online in NOMOS: < http:// lawdb.intrasoftnet.com/index.php $>$.

78 Dodekanese Court of Appeal 307/2005, online in NOMOS: <http://lawdb.intra softnet.com/index.php $>$. 
We did not find a QALY weight for the loss of an eye as such, but there is relevant information to be found in other research. In a publication from 2003 , a cost-utility analysis of cataract surgery in the second eye after successful treatment of the first eye is carried out. ${ }^{79}$ Earlier research already showed that surgery to the first eye is very cost-effective. ${ }^{80}$ Furthermore, different research suggests that the quality of life in patients with bilateral good vision is substantially higher than that of patients with unilateral good vision. ${ }^{81}$ Hence, this research provides information on the difference in QALY value between sight with one eye and sight with two eyes. The total QALY gains of cataract surgery to the second eye per patient are estimated at $1.31 \mathrm{QALY}{ }^{82}$ which is equivalent to $€ 65,500$ if the conservative value of $€ 50,000$ per QALY is used. It is important to note that this cataract research involves older people, who had a remaining life expectancy of 12 years. For younger victims with a longer remaining life expectancy, the total QALY gains will be proportionally higher. The already mentioned literature which compares quality of life between unilateral and bilateral good vision suggests a difference of 0.109 QALY. Hence, for a person with a remaining life expectancy of about 36 years (such as the mother in the Greek case), the total QALY gains would amount to 3.9, resulting in about $€ 107,000$ in pain and suffering damages. ${ }^{83}$ Due to the relatively low estimate of $€ 50,000$ per QALY, the resulting amounts are still comparatively low, but substantially higher than in most European countries, apart from Italy and Greece. What is observable in the case law is that the age of the victim does indeed seem to have an influence. In the German cases, the young age of the victim was explicitly mentioned as a reason to increase the level of damages. And in several Dutch cases, the court also refers to the youth of the victim. ${ }^{84}$

79 BG Busbee et al, Cost-Utility Analysis of Cataract Surgery in the Second Eye [2003] 110 Ophthalmology 2310.

80 BG Busbee et al, Incremental Cost-effectiveness of Initial Cataract Surgery [2002] 109 Ophthalmology 609.

81 MM Brown et al, Quality of Life Associated with Unilateral and Bilateral Good Vision (2001) 108 Ophthalmology 645. This research suggest a QALY difference of 0.08 , while subsequent research of the same authors (Busbee et al (2003) 110 Ophthalmology 2310) results in a QALY difference of 0.109 . We apply the more recent estimation in our numerical example.

82 Busbee et al (2003) 110 Ophtalmology 2310, 2313.

83 The net present value of 36 payments of $€ 5,450$ ( $0.109 X € 50,000)$, applying a discount factor of $4 \%$, equals $€ 107,172$.

84 Lindenbergh (fn 51) $76 \mathrm{ff}$. 


\section{3) Deafness}

The highest awards of pain and suffering damages for ear injuries in the Netherlands are about $€ 42,543$ and $€ 61,828$ for severe deafness to both ears suffered by a child aged 5 and by a baby as the result of medical treatment. ${ }^{85}$

There is extensive cost-utility research regarding cochlear implants, which are hearing devices which are implanted in the inner ear, as opposed to the more traditional acoustic hearing devices. In this research, it is investigated whether cochlear implants increase quality of life enough to be worth their additional cost. Summerfield et al investigated whether bilateral cochlear implants rather than unilateral implants are cost-effective. ${ }^{86}$ The benefits of unilateral cochlear implants include enhanced social and professional participation for adults and increased integration in mainstream education for children. Cochlear implants do not only benefit patients for whom acoustic hearing devices did not work (the 'traditional candidates'), but also improve the hearing of patients who already benefited from acoustic hearing devices (the 'marginal hearing aid users'). Bilateral implants improve the ability to understand speech in noise and to locate sources of sound. In the research, HUI2 was used to measure utilities. The research found that the QALY loss as a result of profoundly impaired hearing (and consequently, speech) is 0.281 for traditional candidates and 0.145 for marginal hearing aid users. ${ }^{87}$

Again assuming a value of $€ 50,000$ per QALY, deafness in both ears would then be assessed at about $€ 14,000$ per year for those who do not benefit from acoustic devices, and $€ 7,250$ for those who do. For the two Dutch cases, again assuming a life expectancy of 78 years, this would result in amounts of about $€ 345,000$ if acoustic devices do not benefit the patient and $€ 178,000$ if they do. ${ }^{88}$

85 Jansen (fn 51) 81.

86 A Quentin Summerfield et al, A Cost-Utility Scenario Analysis of Bilateral Cochlear Implantation [2002] Archives of Otolaryngology Head \& Neck Surgery (Arch Otolaryngol Head Neck Surg) 1255.

87 Ibid, 1259. Research that focused on older patients found a mean increase in utility of 0.24 . This overall increase is based on the HUI2 and consists of +0.15 (hearing), +0.11 (emotion), +0.02 (speech), -0.01 (ambulation), -0.01 (cognition) and -0.01 (pain). See $H W$ Francis et al, Impact of Cochlear Implants on the Functional Health Status of Older Adults (2002) 112 The Laryngoscope 1484. Research that, conversely, focused on children found increases in utility ranging from 0.22 to 0.39 , depending on the method used (time trade-off, visual analogue scale or HUI3). See $A K$ Cheng et al, Cost-Utility Analysis of the Cochlear Implant in Children [2000] The Journal of the American Medical Association (JAMA) 855.

88 Please note that the UK Cochlear Implant Study Group, Criteria of Candidacy for Unilateral Cochlear Implantation in Postlingually Deafened Adults II: Cost-Effectiveness Analysis (2004) 25 Ear and Hearing 342 applied a discount factor of $6 \%$, which 


\section{4) Amputation of foot and lower extremities}

It is difficult to assess pain and suffering damages for amputation of the foot or lower extremities because in many cases the victim also suffers other injuries. In the Netherlands, ${ }^{89}$ a 31-year-old motor driver was involved in a traffic accident which resulted in the amputation of his lower leg. He received almost $€ 56,000$ in a settlement. A 54-year-old woman who was run over by a garbage truck had her left leg amputated just above the knee. She received about $€ 45,500$ in pain and suffering damages. In Germany, a trolley driver received $€ 12,500$ in respect of the amputation of his forefoot in a case in which he was $50 \%$ comparatively negligent. ${ }^{90}$ In a case in which a young woman was involved in a motor accident and had her lower leg amputated, pain and suffering damages were set at $€ 40,000 .{ }^{11}$ In Greece, $€ 150,000$ was awarded to a 27-year-old man after a car accident which resulted in the amputation of his leg right under the knee. ${ }^{22}$ In another traffic accident case, a minor received $€ 170,000$ in pain and suffering damages for having her left leg amputated just below the knee. ${ }^{93}$ However, the court only granted about $€ 58,700$ to a $32-$ year-old man who was involved in a work-related accident and had his lower leg amputated..$^{94}$ In Italy, a man received $€ 135,000$ in pain and suffering damages for amputation of his foot after an accident. ${ }^{95}$

Relevant information on the impact of a foot amputation on quality of life can be found in health economics literature regarding foot ulcers. Increasing preventive efforts in diabetic patients can lower the probability of foot ulcers and amputations, and the research investigates whether these benefits are worth the costs. ${ }^{96}$ Information is provided on the quality of life experienced by people without foot ulcers, patients with ongoing foot ulcers, after primary healing of a foot ulcer, after healing with minor amputation and after healing with major amputation. A possible problem with using this information is that

would lead to amounts of $€ 245,000$ resp $€ 127,000$. This is still significantly higher than the amounts granted in most countries.

89 Jansen (fn 51) 43.

90 Jaeger/Luckey (fn 50) 779.

91 Ibid, 776. The plaintiff claimed $€ 50,000$ but because of the poor financial situation and the lack of insurance of the injurer, who was the victim's boyfriend, the court only granted $€ 40,000$.

92 Drama Court of First Instance 124/2004, online in NOMOS: <http://lawdb.intra softnet.com/index.php $>$.

93 Thessaloniki Court of Appeal 2601/2006, Armenopoulos 2007, 1921.

94 Areios Pagos (Supreme Court) 961/2007, online in NOMOS: <http://lawdb.intra softnet.com/index.php>.

95 Corte di Cassazione (Highest Court of Appeal) no 25751, 24 October 2008, online in De Jure: $<$ http://dejure.giuffre.it/psixsite/PaginePubbliche/default.aspx $>$.

96 See eg G Ragnarson Tellvall/J Apelqvist, Prevention of diabetes-related foot ulcers and amputations: a cost-utility analysis based on Markov model simulations (2001) 44 Diabetologica 2077. 
it is all related to people with a foot ulcer before amputation. Nonetheless, it may be instructive to review the information. The difference in QALY value between people with no ulcer and people who have healed with major amputation is $0.49 .{ }^{97}$ In order to better focus on the impact of the amputation itself, it is in our view better to compare the QALY value of the latter group with those after primary healing of a foot ulcer, and then the difference is 0.29 .

In another research study, it was investigated whether compression stockings in patients with chronic venous stasis are a cost-effective instrument in reducing the probability of recurrence of ulcerations. In that research, the decrease in utility due to amputation of lower extremities is assessed at $0.26 .^{98}$

Yet another research study has regard to limb-threatening ischemia. The decrease in utility due to amputation of lower extremities suffered by patients who were still ambulant after the amputation ranges from 0.3 to 0.35 , depending on if it is compared with the utility of patients who were cured after revascularization or with patients who were only cured after multiple revascularization..$^{99}$ The amputation may involve more than just the foot, which may explain the higher QALY loss.

If we apply the $€ 50,000$ monetary value of a QALY, it again becomes clear that the amounts awarded for pain and suffering damages in the cases discussed are too low from an economic point of view. Using a 0.26 QALY decrease, which is the lowest from the research we have discussed, an amputation in a 54-yearold victim would result in an award of about $€ 211,000$. That amount would be even higher for the younger victims in our examples.

\section{Conclusions}

The conclusion from the above analysis is that pain and suffering damages awarded in legal cases are too low from a health economics perspective. It is not possible to calculate exactly the correct magnitude of such damages, first because there is no consensus over the monetary value of the QALY; secondly, there are different ways to assess the relative weight of different health impairments, leading to divergent results; thirdly, QALYs are intended to evaluate different health programmes, treatment methods and techniques in terms of their cost-effectiveness, not to calculate damages. Notwithstanding

97 Ibid, 2079. Also see G Ragnarson Tellvall/J Apelqvist, Health-related quality of life in patients with diabetes mellitus and foot ulcers (2000) 14 Journal of Diabetes and Its Complications (J Diabetes Complications) 238.

98 P Korn et al, Why insurers should reimburse for compression stockings in patients with chronic venous stasis (2002) 35 Journal of Vascular Surgery (J Vasc Surg) 952.

99 TE Brothers et al, Justification of intervention for limb-threatening ischemia: a surgical decision analysis (1999) 7 Cardiovascular Surgery (Cardiovasc Sur) 65. 
these caveats, we still think that using the information that can be derived from QALY studies is a better method to determine pain and suffering damages than merely looking at the amounts that were awarded in the past. After all, such awards provide no indication of the correctness of the assessment because that requires an external framework. By basing our calculations on a very conservative estimation of the monetary value of a QALY ( $€ 50,000)$, we feel that the resulting amounts do not lead to the overestimation of immaterial losses. This is reinforced by our application of a relatively high discount factor of $4 \%$. Further developments in the health economics literature will therefore in our view more likely lead to upward adjustments of the resulting amounts than downward adjustments.

In order to be able to achieve the goals discussed in our paper, adjustments in pain and suffering damages are required. At current levels of awards, the compensation goal cannot be achieved. After all, if damages should aim at restoring the balance, ${ }^{100}$ they should express the gravity of the losses caused by the injurer. In as far as independent weight is attached to the goal of satisfaction, pain and suffering damages should also be based on the gravity of the immaterial losses. The deterrence goal is also served by such an increase, because currently the injurer does not fully bear the negative consequences of his activities. Hence, in our view, the magnitude of pain and suffering damages should be increased.

We see two possible ways in which the use of QALYs could be implemented in practice, besides the option of mandatory legislation, which we do not advocate. First, lawyers could base the amount of damages which they claim for their clients on health economics literature and/or on information provided by medical experts. Courts would then have to decide whether to grant these higher claims. If they do, these higher amounts will find their way into the currently applied tables with court decisions, so that the QALY approach would, bottom-up, gain ground. The second approach would be to replace the tables with court decisions by the amounts based on QALY research. Given that health economics research often results in an average QALY weight accompanied by an upper and a lower limit, the envisaged QALY-tables would offer a range of amounts rather than a fixed amount. The courts could then use these tables in assessing pain and suffering damages. Our paper provides information on four health conditions, but it should be clear that more health conditions should be evaluated before such tables could be applied. However, it may not be necessary to include all conditions imaginable. For example, if the table included amputation of a foot and amputation of a leg, even if there were no amount included for amputation of a lower leg, it may be assumed that this should lie in between the two others. 
If pain and suffering damages were indeed to be increased, insurance premiums would rise because coverage would have to be extended. The increase in insurance premiums in our view will not lead to uninsurability. That problem is not primarily caused by the size of the insured liability, but rather by the uncertainty of the expected risk. ${ }^{101}$ Health economics insights may lead to an enhanced ability to predict the level of pain and suffering damages, which would lead to better assessment of the expected risks than under the current approach.

Much additional research is needed to provide more clarity regarding the way in which information from cost-effectiveness research of health care can be utilised in tort law, in particular the assessment of QALY weights, the possible problem that some QALY research addresses improvements in health due to medical treatment whereas tort law is concerned with decreases in health due to accidents, ${ }^{102}$ and insights from research regarding adaptation. ${ }^{103}$ Refining the answers to these questions enables a better assessment of pain and suffering damages. We hope that our paper has already made clear that enough reasons exist to regard current awards as too low and hence to increase the level of pain and suffering damages in the future.

$101 M$ Faure, The View from Law and Economics, in: G Wagner (ed), Tort Law and Liability Insurance (2005) 251, 252.

102 This may be relevant due to the issue of loss aversion, which implies that risk averse people weigh a loss of a certain size more heavily than a gain of the same size. If this were taken into account, the QALY values used may still be an underestimation of the losses in question. Note however that much QALY research focuses on the decrease in health due to a certain condition, and investigates whether treatments to avoid the decrease are worth their costs.

103 This research suggests that people have a great capacity to adapt to their situation. This could imply that the utility loss due to deterioration in health decreases over time, because people adapt to (eg) their disability. This issue could be incorporated by (eg) choosing a higher discount factor, or by only using QALY values which are based on patient reports rather than on reports by medical experts or volunteers. After all, patients may provide assessments in which the element of adaptation is already incorporated. 